\author{
Е.И. Голанова \\ Институт русского языка РАН \\ (Россия. Москва) \\ egolanova@yandex.ru
}

\title{
МНОГОЗНАЧНОСТЬ СУФФИКСАЛЬНЫХ УНИВЕРБОВ И ЕЁ ОТРАЖЕНИЕ В ТСРР
}

В статье на материале слов-универбов, широко распространённых в современной русской разговорной речи (ср. времянка, генералка, дежурка, коммуналка, кредитка, манка, овсянка, социалка, экскурсионка и др.) рассматривается проблема многозначности и её отражения, представления в толковых словарях, в частности - ТСРР (Толковом словаре русской разговорной речи). Суффиксальные универбы (представляющие одну из разновидностей явления «универбации») результат действия модели словопроизводства, активно проявляющую себя уже в XIX в. (ср. ночлежка, открытка, путёвка и др.). Слова этого типа возникают на основе определительного компонента словосочетания (обычно это прилагательное + существительное) при помощи суффиксов (-ка, -ик, -ушка, -щчик и др.), образуя синонимичное существительное, новую номинативную единицу. Из однотипности способа словообразования и словообразовательной структуры таких слов, однако, не следует вывод об однотипности их семантической структуры. В основе различия семантической наполненности («однозначности» или «многозначности») слов-универбов лежат различия в характере семантики мотивирующего прилагательного, в степени обобщенности или конкретности его значения. Трудности возникают при подаче в словаре слов-универбов, образованных от прилагательных с широким, обобщающим значением, выражающих лишь общую идею отношения к предмету. При толковании в словарной статье слов этого типа возникают вопросы соотношения разных значений, соотношения многозначности и омонимии. Снять многие неясности, неопределённости помогает понятие «диффузности значений», предложенное в работах Д. Н.Шмелёва.

Ключевые слова: универбация, универбы, словообразовательная модель, словарная статья, семантическая структура, многозначность, диффузность значений.

В современной русской разговорной речи активно используются однословные номинации, заменяющие составные наименования: аскорбинка, ветрянка, 
времянка, газировка, гуманитарка, маршрутка, бюджетник, глазник, мобильник, спальник, раскладушка, газовщик, коммунальщик и под.

Такие слова-универбы возникают как результат действия широко распространённого в русском языке способа словопроизводства, когда из словосочетания (обычно это прилагательное + существительное) на основе его определительного компонента при помощи суффиксов (-ка, -ик, -ушка, -щзик и др.) создаётся синонимичное существительное, новая номинативная единица. Ср., например: «Проезд по карте «Тройка» в метро и наземке подорожает всего на один рубль» («На Западе Москвы», янв. 2018).

Этот способ образования слов относят обычно к явлению «универбации» (лат. unus - один, verbum - слово), на которое исследователи обратили внимание ещё в 60-80-е гг. прошлого века (Земская 1968, Лопатин 1973, Голанова 1982 и др.), отметив и такие типы, как аббревиация, субстантивация, сложение. Наиболее активной оказалась суффиксальная универбация, причём эта словообразовательная модель проявила себя уже в ХІХ в., о чём писал акад. В.В. Виноградов: «В русском литературном языке со второй половины XIX в. всё более и более укреплялась тенденция синонимического замещения литературных словосочетаний, состоящих из имени прилагательного и существительного, разговорными новообразованиями от основ соответствующих прилагательных... Поэтому в фамильярной речи выражение квасной naтриот порождает слово квасник» [Виноградов 1994, 242]. Примерно в то же время в театральной среде Петербурга возникают Мариинка (Мариинский оперный театр) и Александринка (Александринский драматический театр). Появляются в начале XX в. и завоёвывают своё пространство в системе номинации такие слова, как грузовик, конка, многоместка, открытка, путёвка, и др.

О продуктивности этой модели в современном языке свидетельствуют многочисленные номинации, возникающие почти автоматически из составных наименований, свойственных разным сферам современной жизни: гриппозник, вечерник, зачётка, дежурка, кредитка, манка, микроволновка, наземка, наличка, нержавей$\kappa a$, платёэка, сменка, сочичалка, сольник, спальник, техничка, экскурсионка, ювелирка и т. п.

Из однотипности способа словообразования и словообразовательной структуры таких слов, однако, не следует вывод об однотипности их семантических структур. В основе различия семантической наполненности («однозначности» или «многозначности») слов-универбов лежат различия в характере семантики мотивирующего прилагательного, в степени обобщённости или конкретности его значения. Так, выделяются имена с высокой степенью «прозрачности мотивации»: купальник (купальный костюм), спальник (спальный мешок), кругосветка (кругосветное путешествие), миллиметровка (миллиметровая бумага - размеченная на клетки в 1 кв. мм), микроволновка (микроволновая печь), подсобка (подсобное помещение), попутка (попутная машина), продлёнка (продлённый день - группа продлённого дня) и т.п. Однозначность, конкретность семантики словообразующего прилагательного определяет однозначность новой номинации, способствует закреплению у вновь образованного существительного одного устойчивого 
лексического значения, что находит адекватное отражение в толковых словарях, в том числе в «Толковом словаре русской разговорной речи» (ТСРР).

Трудности возникают при подаче в словаре слов-универбов другого типа (таких, как визитка, генералка, дежурка, дорожник, зимник, коммуналка, социалка, технич$\kappa a$ и под.), образованных от прилагательных с широким, обобщающим значением, выражающих лишь общую идею отношения к предмету (ср. генеральнылй, дежурный, дорожный, зимний и т.д.). Здесь возникают вопросы соотношения разных значений слова, соотношения многозначности и омонимии, многозначности и однозначности.

Как пишет Д.Н. Шмелёв, «понятие лексической многозначности может быть противопоставлено не только понятию омонимии, но и понятию однозначности... Признание многозначности слов, основанное как на непосредственном применении языка... так и длительной лексикографической практике, не означает, однако, того, что между многозначностью и омонимией объективно существует какая-то четкая и ясно очерченная граница, которую следует только, наконец, обнаружить» [Шмелёв 1973: 87].

Современная лексикографическая практика пока не представляет единства в отношении многозначных слов. Для снятия многих трудностей Д.Н. Шмелёв вводит понятие «диффузности», отмечая, что: «принцип диффузности значений многозначного слова является решающим фактором, определяющим его семантику. То, что лексикографические описания не отражают этого (более того, напротив, стремятся освободить словарные статьи от «неопределённых» примеров) существенно искажает представление о семантической структуре описываемых слов» [Шмелёв 1973: 95].

В задачи ТСРР входит с возможной полнотой дать лексикографическое описание современной разговорной речи. Имена, созданные на основе суффиксальной универбации, занимают своё законное место в этом словаре. Сложности их толкования хорошо видны на примере универба коммуналка. Словарное описание этого слова в ТСРP (выпуск 2, M., 2017) дано следующим образом: 1. DEF: коммунальная квартира... 2. DEF: коммунальные услуги... 3. DEF: плата за коммунальные услуги... В примере-иллюстрации читаем: «Но для них есть социальное жильё, где цены на обслуживание более низкие, на «коммуналку» даются скидки». «Коммуналка» здесь может восприниматься или как 'коммунальные услуги', или как 'плата за коммунальные услуги'.

В то же время в Проспекте Толкового словаря русской разговорной речи (М., 2010) в пробных словарных статьях этот универб представлен иначе — в виде двух омонимов: КОММУНАЛКА ${ }^{1}$. DEF: коммунальная квартира... КОММУНАЛ$\mathbf{K A}^{2}$. 1. DEF: сфера коммунально-бытового обслуживания городского населения... 2. DEF: коммунальные платежи...

Приведённые выше толкования ещё раз подчёркивают тот факт, что неоднозначность, сложность семантики слова создаёт предпосылки для появления различий в его словарных описаниях в разных лексикографических трудах.

Можно привести ещё ряд ярких примеров «диффузных» универбов. Так, слово социалка, в словарях толкуется как 'социальная сфера' (см., например, Толковый словарь русского языка начала XXI века. М., 2007). В Проспекте ТСРР тоже 
отмечается одно это значение: «социальная сфера государства (здравоохранение, образование, культура, коммунально-бытовое обслуживание и т.п.)». Однако в современной разговорной речи этот универб используется и в более узком смысле, как замена словосочетания «социальная помощь», ср: (Разговор двух пенсионерок:) - Тьл социалкой пользуешься? - Нет / ещзё не оформила //.

Показательный пример диффузности семантики даёт и группа названий круп и каш (суф. -ка). В следующем тексте: Овсянка / находка для туриста // - Считай/ перловка тоже сгодится // — можно увидеть разные значения слов этой группы.

Подобные примеры наглядно показывают важность отражения в толковых словарях диффузности значений многозначного слова.

\section{Литература}

Виноградов В. В. История слов. Институт русского языка РАН, М. : Толк, 1994.

Голанова Е. И. Производное слово как номинативная единица // Способы номинации в современном русском языке. М. : Наука, 1982.

Голанова Е. И. Как возникают названия. М. : Просвещение, 1989.

Земская Е. А. Русская разговорная речь. Проспект. М. : 1968.

Земская E. A. Русская разговорная речь. Лингвистический анализ и проблемы обучения. М. : Русский язык, 1987.

Лопатин В. В. Рождение слова. М. : Наука, 1973.

Лопатин B. В. Суффиксальная универбация и смежные явления в сфере образования новых слов // Новые слова и словари новых слов. Л.: Наука, 1978.

Шмелёв Д. Н. Внешние и внутренние факторы семантических изменений // Лексика современного русского литературного языка. М. : Наука, 1968.

Шмелёв Д. Н. Проблемы семантического анализа лексики. М. : Наука, 1973.

\section{E. I. Golanova}

V.V. Vinogradov Russian Language Institute (Russian Academy of Sciences)

(Russia. Moscow)

egolanova@yandex.ru

\section{POLYSEMY OF SUFFIXAL UNIVERBS AND ITS REPRESENTTIONS IN THE EDRES}

The article addresses the problem of univerbs polysemy and its representations in explanatory dictionaries, in particular the EDRES (The Explanatory Dictionary of Russian Everyday Speech). Univerbs are widespread in modern Russian colloquial speech (cf. vremyanka 'temporary shelter', generalka 'general rehearsal', dezhurka 'duty room', communalka 'communal payments', creditka 'credit card', manka 'semolina', ovsyanka 'oatmeal', socialka 'social sphere', excursionka 'excursion service', etc.).

Suffixal univerbs (representing one variety of univerbs) are formed according to word formation pattern that actively manifested itself in the 19th century (cf. nochlezhka 
'flophouse', otkrytka 'postcard', putevka 'voucher', etc.). Words of this type derived on the basis of a phrase (usually an adjective + noun) by means of suffixes $(-k a,-i k$, -ushka, -shchyk, etc.) become are new nominative units synonymous to already existing nouns. Thus, the word sgushchenka 'condenced milk' is formed from the phrase sgushchennoye moloko 'condenced milk' on the basis of the adjective sgushchennoye and the suffix $-k a$.

However, the similarity of the way of word formation and of the morphological structure of such words does not imply the similarity of their semantic structures. The origin of the difference in univerbs semantic structure ("monosemy" or "polysemy") lies in the nature of the motivating adjective meaning, in particular in the degree of its generality or concreteness. Difficulties emerge when one tries to produce lexicographic definitions of univerbs derived from adjectives with a broad, generalized meaning expressing only the most general idea of the relationship to the subject. There arise questions of the relationship between different word meanings, as well as of polysemy and homonymy. D. N. Shmelev in his works put forward the concept of "diffuse semantics" which helps to remove many ambiguities and uncertainties.

Keywords: univerb, word-formation pattern, dictionary entry, semantic structure, polysemy, diffusion of meanings

\section{References}

Vinogradov V. V. Istoriya slov [History of words] Moscow, Tolk Publ., 1994, 1138 p.

Golanova E.I. [A derived word as A nominative unit] Sposoby nominatsii v sovremennom russkom yazyke [Ways of nomination in modern Russian], Moscow, Nauka Publ. 1982, 238 p. (In Russ.)

Golanova E. I. Kak voznikayut nazvaniya [How names appear], Moscow, Prosveshchenie Publ. 1989, 142 c.

Zemskaya E. A. Russkaya razgovornaya rech'. Prospekt [Russian everyday speech. Prospectus], Moscow, Nauka Publ., 1968. 130 p.

Zemskaya E. A. Russkaya razgovornaya rech'. Lingvisticheskiy analiz i problemy obucheniya [Russian everyday speech. Linguistic analysis and teaching problems]. Moscow, Russian language Publ., 1987. 240 p.

Lopatin V. V. Rozhdeniye slova [The Birth of a word]. Moscow, Nauka Publ., 1973. $152 \mathrm{p}$.

Lopatin V.V. [Suffixal Univerbs and Related Phenomena in the Sphere of the Formation of New Words]. Novye slova i slovari novykh slov [New words and dictionaries of new words]. Leningrad, Nauka Publ., 1978. 184 p.

Shmelev D. N. [External and internal factors of semantic changes]. Leksika sovremennogo russkogo literaturnogo yazyka [Lexicon of the modern Russian Standard language]. Moscow, Nauka Publ., 1968. 185 p.

Shmelev D. N. Problemy semanticheskogo analiza leksiki [Problems of vocabulary semantic analysis]. Moscow, Nauka Publ., 1973. 278 p. 